\title{
Influence of the densities and nutritional components of bacterial colonies on the culture-enriched gut bacterial community structure
}

\author{
Yanrong Gu${ }^{1,2}$, Dong Yan ${ }^{1 *} \mathbb{D}$, Minna Wu${ }^{1}$, Min $\mathrm{Li}^{1}$, Puze $\mathrm{Li}^{1}$, Jingjing Wang ${ }^{1}$, Yahan Chang ${ }^{1}$, Fan Yang ${ }^{1}$, \\ Shaojun Di ${ }^{1}$, Shijun $\mathrm{Ni}^{1}$, Mengjie Yang ${ }^{1}$ and Jieyu Liu ${ }^{1}$
}

\begin{abstract}
Isolating relevant microorganisms is still a substantial challenge that limits the use of bacteria in the maintenance of human health. To confirm which media and which bacterial colony densities can enrich certain kinds of bacteria, we selected eight common media and used them to enrich the gut microorganisms on agar plates. Then, we calculated the numbers of bacterial colonies and collected the bacterial culture mixtures from each kind of medium. Using the Illumina HiSeq platform, we analyzed the composition and diversity of the culture-enriched gut bacterial community. Our data suggested that medium supplemented with blood could increase the diversity of the bacterial community. In addition, beef powder and peptone could significantly change the culture-enriched bacterial community. A moderate density (100-150 colony-forming units per plate) was optimal for obtaining the highest diversity on the agar. Similarly, membrane transport was significantly enriched in the moderate-density group, which indicated a more active metabolism in this density range. Overall, these results reveal the optimal culture conditions, including the densities of colonies and nutritional components for various gut bacteria, that provide a novel strategy for isolating bacteria in a way that is targeted and avoids blinded and repetitive work.
\end{abstract}

Keywords: Culture-enriched, Gut bacterial community, Culture methods, Diversity, Nutritional components of media, Density

\section{Introduction}

The important role of the gut microbiota in human health is becoming abundantly apparent. It is believed that the $1-2 \mathrm{~kg}$ of microorganisms in the human gut contain 150 times more genes than the human genome itself (Bäckhed et al. 2005; Patterson et al. 2016; Qin et al. 2010). The occurrence of many diseases, such as diabetes, obesity, and colorectal cancer, is related to the gut

\footnotetext{
*Correspondence: yand26@163.com

${ }^{1}$ Xinxiang Key Laboratory of Pathogenic Biology, Department

of Microbiology, School of Basic Medical Sciences, Xinxiang Medical University, 601 Jinsui Road, Hongqi District, Xinxiang 453003, Henan, China

Full list of author information is available at the end of the article
}

microbiota (Patterson et al. 2016; Qin et al. 2012; Wong and $\mathrm{Yu}$ 2019). In addition, the gut microbiota influence inflammation and immunity both locally and systemically (Abt et al. 2012; Clemente et al. 2012; Takeshi et al. 2011), and they have been demonstrated to contribute to cancer therapy (Iida et al. 2013). The development of omics technologies, beginning with metagenomics, highlighted the relationship between gut bacteria and human health. However, genomic technologies have provided a limited perspective as they cannot easily detect the minority populations (Lagier et al. 2012). A previous study has revealed that $80 \%$ of gut bacteria are unknown and considered unculturable (Lagier et al. 2018), which has made it difficult to further uncover the relationship between 
gut bacteria and disease. It is difficult to elucidate the role of microorganisms in human health without the ability to culture some microorganism. Therefore, because of their importance of unculturable microorganisms, the methods that isolate them have received more attention.

Culture methods for isolating unculturable microorganisms have been improved in previous studies. For in situ culture, the natural habitats of the targeted microorganisms could be mimicked. For example, Jung et al. developed a new technique, I-tip, which permitted microorganisms to grow utilizing chemical compounds in their natural environment, and it narrowed the gap between cultivated and uncultivated species (Jung et al. 2015). Furthermore, microbial interactions are important for population viability, and microorganisms can cooperate with each other by releasing metabolites and signaling molecules. Substances such as humic acid, signaling molecules, enzymes (for coping with reactive oxygen species), or inhibitors of undesired organisms (Alain and Querellou 2009; Leadbetter et al. 1999; Stevenson et al. 2004) were added to the medium, and more unculturable microorganisms were collected. In recent years, microbial culturomics has been a culturing approach that uses multiple techniques, such as MALDi-TOF mass spectrometry and 16S rRNA sequencing, for the identification of bacterial species. Using culturomics techniques, many microorganisms were isolated that had previously been considered unculturable (Lagier et al. 2016).

In this study, to ensure the consistency of fecal samples, we selected the commonly used mouse model BALB/c. We investigated how the nutritional components and densities influence the composition and diversity of the bacterial community, which bacteria could be enriched and the conditions of nutritional composition or density that allowed enrichment, and what the interaction was among bacteria at various densities. Thus, on the basis of these results, we determined a definite medium for the future isolation of a targeted bacterium in a certain density of bacterial colonies.

\section{Materials and methods}

\section{Mice fecal samples collection}

Three 6-week-old male BALB/c mice were purchased from Beijing Vital River Laboratory Animal Technology Co., Ltd. (Beijing, China). For environmental adaptation, mice were housed for 1 week before the experiment. Mice were housed in individually ventilated caging systems under a 12-h light/dark cycle at an environmental temperature of $23^{\circ} \mathrm{C} \pm 2{ }^{\circ} \mathrm{C}$ and a humidity of $55 \% \pm 5 \%$, and the mice had free access to sterilized standard rodent chow food and sterilized water. Three fecal samples were collected from each of the three mice. A $0.1 \mathrm{~g}$ sample of feces was resuspended in $1 \mathrm{~mL}$ of sterile saline and homogenized for $5 \mathrm{~min}$ using a vortex 10-diluted fecal suspension. Another $0.1 \mathrm{~g}$ of feces was stored in a $-80^{\circ} \mathrm{C}$ refrigerator. After the study, all the mice were euthanized by cervical dislocation and subsequently treated as nonhazardous waste. Animal care was performed according to the National Institutes of Health's Guide for the Care and Use of Laboratory Animals, and the experimental protocol was approved by the Institutional Animal Care and Use Committee of Xinxiang Medical University.

\section{Cultivation of fecal bacteria}

For each $10^{6}$ - and $10^{7}$-diluted fecal suspension, $100 \mu \mathrm{L}$ was spread-plated onto eight kinds of medium plates, namely, modified Gifu anaerobic medium (GAM) (Haibo, China), brain-heart infusion medium (BH) (Haibo, China), chopped meat medium (CM) (Haibo, China), nutrient agar medium (NA) (Haibo, China), tryptic soy agar medium (TSA) (Haibo, China), reinforced Clostridial medium (RCM) (Haibo, China), Mueller-Hinton medium (MH) (Haibo, China), and blood medium (BL) (Huankai, China). As a control group, the fecal suspensions left were stored at $-80{ }^{\circ} \mathrm{C}$. The nutritional components of each medium are listed in Table 1. Eight replicates of each fecal sample were spread-plated onto each medium. Plates were then incubated anaerobically at $37^{\circ} \mathrm{C}$ in an anaerobic workstation $\left(10 \% \mathrm{CO}_{2}, 10 \% \mathrm{H}_{2}\right.$, and $80 \% \mathrm{~N}_{2}$ ). To keep the oxygen concentration below $0.1 \%$, the oxygen concentration was detected every day. After $72 \mathrm{~h}$ of incubation, the number of colony-forming units (CFUs) was counted.

\section{DNA extraction and PCR amplification}

The plates with a single bacterial colony diameter that was greater than $1 \mathrm{~cm}$ were discarded. Thus, we collected the bacterial colonies in the plates of each medium and each dilution and added them into a $2 \mathrm{~mL}$ centrifuge tube using normal saline. The supernatant was discarded after centrifugation for $10 \mathrm{~min}$ at $7000 \mathrm{~g}$. Genomic DNA of bacterial colony mixtures and uncultured fecal samples (control group) was extracted using the Biomiga Stool gDNA Miniprep kit (Biomiga, USA) according to the manufacturer's protocols. The V3-V4 region of the bacterial rRNA gene was amplified by PCR $\left(98^{\circ} \mathrm{C}\right.$ for $1 \mathrm{~min}$, followed by 30 cycles at $98{ }^{\circ} \mathrm{C}$ for $10 \mathrm{~s}, 50{ }^{\circ} \mathrm{C}$ for $30 \mathrm{~s}, 72{ }^{\circ} \mathrm{C}$ for $30 \mathrm{~s}$ and a final extension at $72{ }^{\circ} \mathrm{C}$ for $5 \mathrm{~min}$ ) using the primers 338F (5'-ACTCCTACGGGAGGCAGCAG-3') and 806R (5'-GGACTACHVGGGTWTCTAAT-3') (Huws et al. 2007), where the barcode was a 6-base sequence unique to each sample. PCR amplification was conducted using Phusion High-Fidelity PCR Master Mix (New England Biolabs, USA). GeneJET Gel Extraction Kit (Thermo Scientific, USA). Amplicons were purified using the GeneJET Gel Extraction Kit (Thermo Scientific, USA). 
Table 1 The composition of each medium (g)

\begin{tabular}{|c|c|c|c|c|c|c|c|c|}
\hline & GAM & RCM & $\mathrm{BH}$ & NA & CM & TSA & BL & $\mathrm{MH}$ \\
\hline Peptone & 28 & 10 & 21 & 10 & 30 & 20 & 10 & 17.5 \\
\hline Phosphate & 2.5 & 0 & 2.5 & 0 & 5 & 2.5 & 0 & 0 \\
\hline Yeast extract powder & 5 & 3 & 0 & 0 & 5 & 0 & 0 & 0 \\
\hline Beef powder & 2 & 10 & 0 & 3 & 3 & 0 & 10 & 2 \\
\hline Beef liver extract powder & 1.2 & 0 & 0 & 0 & 0 & 0 & 0 & 0 \\
\hline Beef brain extract powder & 0 & 0 & 4 & 0 & 0 & 0 & 0 & 0 \\
\hline Beef heart extract powder & 0 & 0 & 4 & 0 & 0 & 0 & 0 & 0 \\
\hline Soluble starch & 0.3 & 1 & 0 & 0 & 2 & 0 & 0 & 1.5 \\
\hline L-Cysteine & 0.15 & 0.5 & 0 & 0 & 0 & 0 & 0 & 0 \\
\hline Glucose & 3 & 5 & 2 & 0 & 3 & 2.5 & 0 & 0 \\
\hline Serum powder & 13.5 & 0 & 0 & 0 & 0 & 0 & 0 & 0 \\
\hline Sodium thioglycolate & 0.15 & 0 & 0 & 0 & 0 & 0 & 0 & 0 \\
\hline Sodium chloride & 3 & 5 & 5 & 5 & 0 & 5 & 5 & 0 \\
\hline Sodium acetate & 0 & 3 & 0 & 0 & 0 & 0 & 0 & 0 \\
\hline Chopped meat & 0 & 0 & 0 & 0 & 1 & 0 & 0 & 0 \\
\hline Defidrinated sheep's blood & 0 & 0 & 0 & 0 & 0 & 0 & $80(\mathrm{~mL})$ & 0 \\
\hline
\end{tabular}

\section{Illumina HiSeq sequencing}

Sequencing libraries were generated using an Illumina TruSeq DNA PCR-Free Library Preparation Kit (Illumina, USA) following the manufacturer's recommendations, and index codes were added. Finally, the qualified libraries were sequenced on an Illumina HiSeq2500 platform belonging to Novogene Co. Ltd (Beijing, China), which generated $250 \mathrm{bp}$ paired-end reads.

\section{Processing of sequencing data and statistical analyses}

The raw read sequences were demultiplexed, qualityfiltered, and dereplicated using vsearch (version 2.8.1). The operational taxonomic units (OTUs) were clustered using vsearch based on the UNOISE algorithm (Edgar 2016). QIIME 2 was used to analyze $\alpha$ diversity, $\beta$ diversity and the taxonomy of each $16 \mathrm{~S}$ rRNA gene sequence against the SILVA (SSU132) 16S rRNA database (Bolyen et al. 2019). Alpha diversity was estimated by Shannon, Faith_PD, evenness, and the observed OTU indices using QIIME 2 (Bolyen et al. 2019). Canonical correspondence analysis (CCA) was conducted using $\mathrm{R}$ software (version 3.7.0) with the vegan package (Team 2018). The heatmaps were plotted using $\mathrm{R}$ software (version 3.7.0). The bar and line graphs were plotted using Origin software (version 8.0). Welch's t tests were performed using the statistical analysis of metagenomics profiles software (STAMP) (Parks et al. 2014) to identify significantly different genera and predictive functions between groups. The network was generated using the CoNet plugin version 1.0b7 for Cytoscape v 3.6.0 based on the nonparametric Spearman correlation coefficients with a minimal cutoff threshold of $\rho=0.8$ $(p<0.05$, Bonferroni corrected) (Faust et al. 2012; Saito et al. 2012). The online Galaxy version of the phylogenetic investigation of communities by reconstruction of unobserved states (PICRUSt, http://huttenhower.org/ galaxy/) was used to predict the metagenome function (Langille et al. 2013).

\section{Strain isolation using TSA and TSA supplemented with $8 \%$ defibrated sheep blood medium}

To confirm the role of blood in the cultivation of fecal samples, bacterial isolates of fecal samples were identified and analyzed on TSA and TSA that were supplemented with $8 \%$ defibrated sheep blood medium. A $100 \mu \mathrm{L}$ sample of each $10^{5}$-diluted fecal suspension was spreadplated onto the two kinds of media. Plates were then incubated anaerobically at $37^{\circ} \mathrm{C}$ in an anaerobic workstation $\left(10 \% \mathrm{CO}_{2}, 10 \% \mathrm{H}_{2}\right.$, and $\left.80 \% \mathrm{~N}_{2}\right)$. Three replicates of each fecal sample were spread-plated in each medium. After $72 \mathrm{~h}$ of incubation, 20 colonies in each plate were picked randomly and purified, but some colonies could not grow in the process of purification culture. Colony PCR amplification of the 16S rRNA gene was performed with methods described by Li et al. (Li et al. 2007). The purified PCR products were sequenced with an ABI PRISM automatic sequencer (model 3730XL). The partial $16 \mathrm{~S}$ rRNA gene sequences (first $61-720 \mathrm{bp}$ ) were compared with the available $16 \mathrm{~S}$ rRNA gene sequences from GenBank for identification using the BLAST program and a web-based tool at http://www.ezbiocloud.net as described by Kim et al. (Yoon et al. 2017). 


\section{Results}

Medium changed the diversity and composition of the gut bacterial community

We obtained 4,291,005 combined raw reads and 1,848,155 valid reads after completing the demultiplexing and quality filtering. The valid reads were clustered into 606 unique OTUs.

The alpha diversity was estimated by the Shannon, Faith PD, observed OTUs, and evenness index. The rarefaction curves indicated that the high-throughput sequencing had captured the dominant phylotypes (Additional file 1: Fig. S1). As we expected, the diversities of the cultured gut bacterial community were significantly lower than those in uncultured feces. Based on the Shannon, observed OTUs, and evenness index results, the highest diversity and richness were observed in $\mathrm{BL}$ medium compared to other media. Furthermore, based on the Shannon and Faith PD index, we found higher diversity in the CM and RCM mediums and lower diversity and richness in the other media. These results indicated that the medium influenced the diversity of the gut bacterial community after the anaerobic cultivation (Fig. 1a-d).

We assessed the composition of the gut bacterial community using principal coordinate analysis (PCoA). As shown in Fig. 1e, the uncultured fecal composition of the gut bacterial community was clustered together, and the cultured fecal composition of the gut bacterial community was clustered together in BL, GAM, and NA medium and in $\mathrm{BH}, \mathrm{CM}, \mathrm{MH}, \mathrm{RCM}$, and TSA, which indicated that the medium influenced the composition of the gut bacterial community.

The bacterial community of the uncultured feces was dominated by Lactobacillus (21.2\%), Ruminococcaceae UCG-014 (10.8\%), Muribaculaceae uncultured bacterium (8.9\%), Staphylococcus (8.7\%), Lachnospiraceae NK4A136 group (6.7\%), and Alistipes (6.2\%). The bacterial community of the cultured feces was dominated by Staphylococcus (27.9\%), Lactobacillus (18.3\%), Citrobacter (16.3\%), Aerococcus (7.5\%), and Bacteroides (7.1\%) (Fig. 2a, Additional file 2: Table S1). Large differences in the relative abundance of the genera were observed between the uncultured (Control) and cultured fecal samples using heatmap analysis; for example, Ruminococcaceae UCG-014, Muribaculaceae uncultured, Alistipes, Lachnospiraceae NK4A136 group, Lachnospiraceae uncultured, Enterorhabdus, Candidatus Saccharimonas, and Parasutterella were largely increased in the uncultured fecal samples and decreased in the cultured fecal samples, which indicated that these genera were hard to isolate in vitro; however, Enterococcus, Aerococcus, Acinetobacter, Bacteroides, Lactobacillus, and Staphylococcus showed similar abundances in the uncultured and cultured fecal samples, which indicated that these genera were easier to isolate in vitro (Fig. 2b). Importantly, we identified the significant genera from different media using statistical analysis of metagenomics profiles software (STAMP). Compared to the other media, more significant genera were observed in the BL medium. For example, Bacteroides was significantly increased in the $\mathrm{BL}$ medium compared to the MH, NA, and RCM mediums; Corynecbacterium 1, Lactobacillus, and Lactococcus were significantly increased in the $\mathrm{BH}, \mathrm{CM}$, and TSA, respectively, compared to the $\mathrm{BL}$ medium (Fig. 2c). Therefore, the results suggested that nutritional preferences changed the gut bacterial community on the agar plates.

\section{The concentration of beef powder, defibered sheep blood, yeast extract powder, and peptone and the number of colony-forming units (CFUs) significantly influenced the composition of the gut bacterial community}

The nutritional components of each medium are listed in Table 1. Cluster and correlation analysis based on the nutritional components of media showed the differences in the media. The BL medium was clustered into a single group, the NA and RCM medium were clustered into another group, and the GAM, CM, MH, BH, and TSA medium were clustered into a third group (Additional file 1: Fig. S2). Furthermore, we used canonical correspondence analysis and permutation tests (Table 2) to investigate which main nutritional components in the medium significantly influenced the bacterial composition (CCA, Fig. 2d). CCA showed that beef powder and defibered sheep blood were highly significantly correlated with the composition of the bacterial community $(\mathrm{P}<0.01)$; yeast extract powder and CFU were significantly correlated with the composition of the bacterial community $(\mathrm{P}<0.05)$. The beef powder, blood, and CFU showed similar patterns of impacting the composition of the bacterial community, which correlated positively with Alistipes, Proteus, Bacillus, Phyllobacterium, Bacteroides, and Enterococcus. The yeast extract powder and peptone were positively correlated with Clostridium sensu stricto 7, Brevundimonas, Sporosarcina, Clostridium sensu stricto 7, Parabacteroides, Muribaculum, etc. These

(See figure on next page.)

Fig. 1 Diversity and composition of cultured gut bacterial communities in various media and uncultured feces. Shannon (a), faith pd (b), observed OTUs (c), and evenness index (d) in various media and uncultured feces. Boxes show medians and interquartile ranges (IQRs); whiskers denote lowest and highest values within 1.5 times the IQR from the first and third quartiles; outliers are shown as individual points. e Principal co-ordinates analysis (PCOA) of fecal cultured communities in various media and uncultured feces 

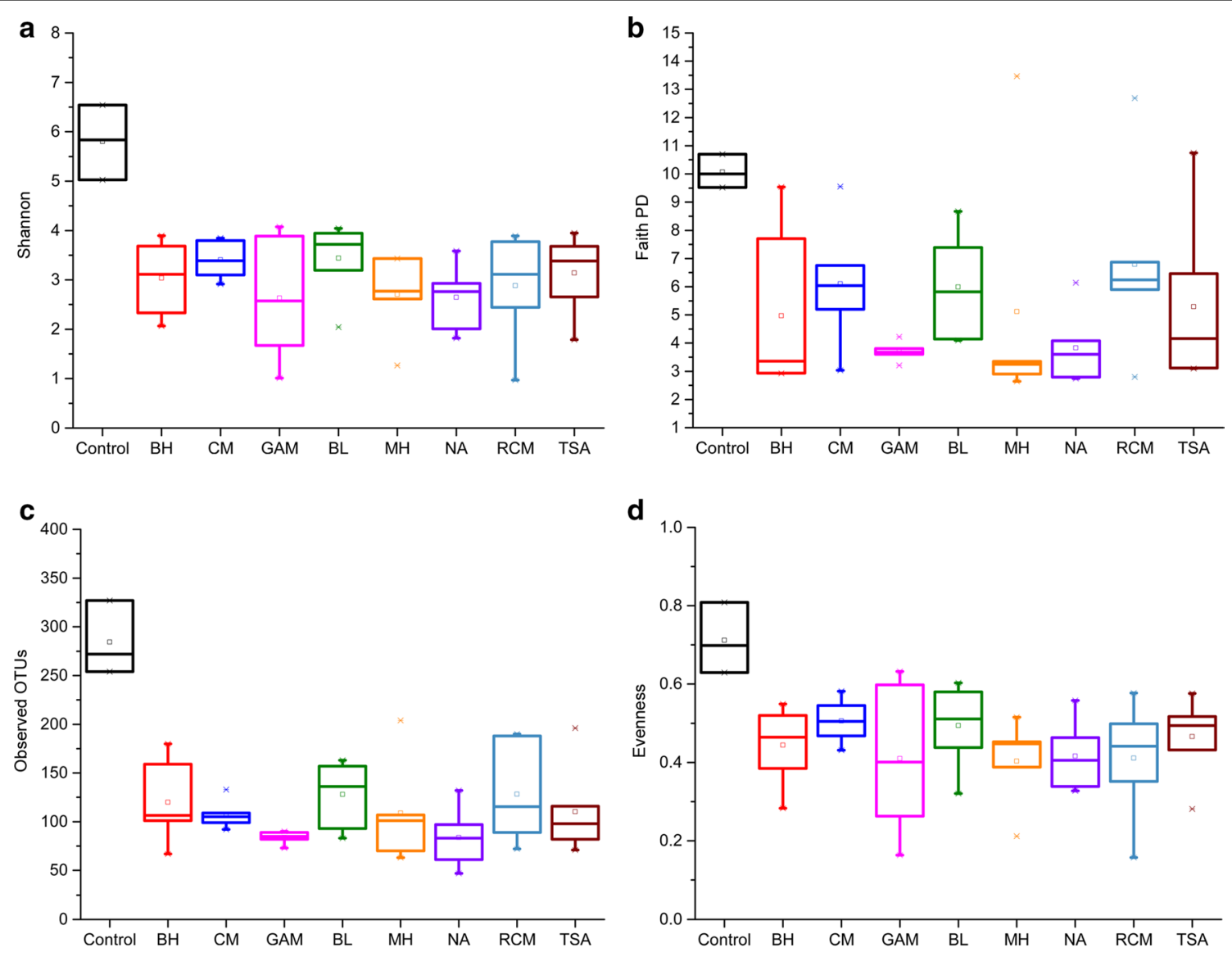

e

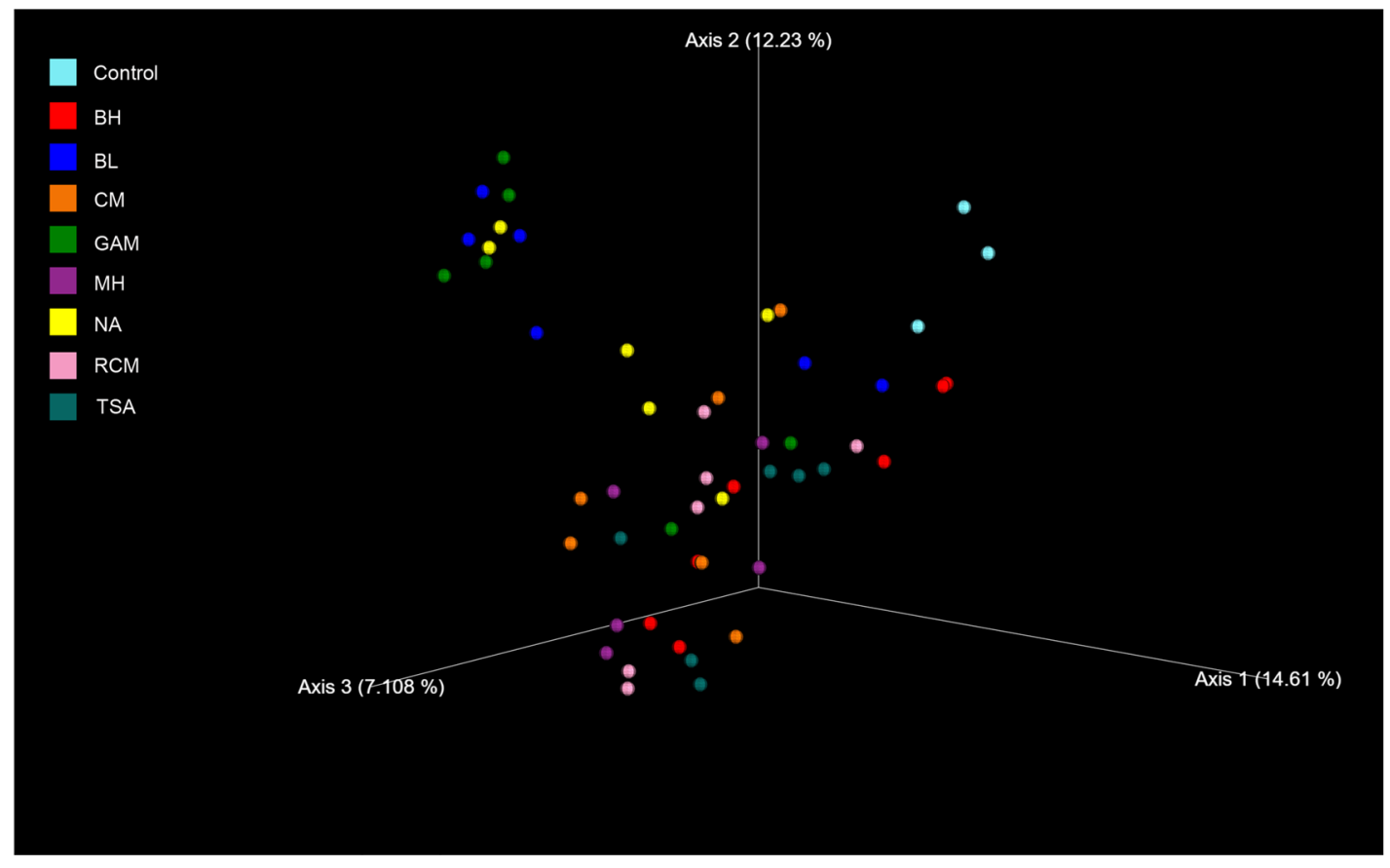


results indicated that the concentration of these components and the number of CFUs influenced the composition of the cultured bacterial community.

To confirm the role of blood in the cultivation of fecal samples, bacterial isolates of fecal samples on TSA medium with and without $8 \%$ defibrated sheep blood were identified and analyzed. Forty strains, which belong to Lactobacillus (95\%), Staphylococcus (2.5\%), and Bifidobacterium (2.5\%) (Table 3), were isolated, purified, and sequenced from the TSA medium. Twenty-nine strains, which belong to Lactobacillus (65.5\%), Parabacteroides (20.7\%), Bacteroides (6.9\%), Phocaeicola (3.4\%), and Parasutterella (3.4\%) (Table 4), were isolated, purified, and sequenced from the TSA medium with $8 \%$ defidrinated sheep blood. These results indicated that supplementation with defidrinated sheep blood increased the diversity and structure of the culture-enriched gut bacterial community. For example, Bacteroides were isolated from the TSA medium with defidrinated sheep blood.

\section{Density of bacterial colonies influenced the diversity and composition of the gut bacterial community}

The number of CFUs influenced the composition of the cultured bacterial community, which suggested that the density of bacterial colonies was a key factor influencing the bacterial community on the agar. According to the numbers of CFUs, we classified the cultured fecal samples into low- (1-50 CFUs/plate), moderate- (51-150 CFUs/plate), and high-density (>151 CFUs/plate) groups (Additional file 2: Table S2). A higher Faith PD and evenness index were observed in the moderate-density samples, yet no significant differences were observed in the Shannon and observed OTU index, which indicated that moderate density increased the diversity and evenness (Fig. 3a-d).

PCoA indicated that low-density and moderate-density samples clustered separately (Fig. 3e). Thus, we assessed the significant genera in the low-, moderate-, and high-density groups using STAMP. Proteus, Alistipes, and Enterococcus were significantly increased in the high-density group compared to the low-density group; Citrobacter and Enterorhabdus were increased in the moderate-density group compared to the low-density group; and Proteus, Clostridium s.s. 13, and Clostridium s. s. 7 were increased in the high-density group compared to the moderate-density group (Fig. 3f).

\section{Bacterial interactions among the gut bacterial community on agar plates}

To compare the possible interactions among the low-, moderate-, and high-density samples on the agar plates, the 98 genera we detected were used to construct three networks. In the resulting network, each node was a bacterial genus, and the edges indicated significant cooccurrent (green) or mutual exclusion (red) interactions (Fig. 4). The greatest number of nodes (44 nodes) and edges (151 edges) were observed in the high-density samples (Table 5). Furthermore, mutual exclusion interactions (18 edges) were only found in the network of high-density samples, which indicated that a high density of bacterial colonies could promote the interactions among the bacterial community and it might be more possible for them to inhibit bacterial growth.

Topological properties are always used in network analyses to describe the complex pattern of interrelationships. High-density samples have the shortest average path length (average network distance, 1.93) and the highest clustering coefficient (the degree to which they tend to cluster together, 0.67), which indicated that high-density samples had the stronger interaction between the nodes (Table 5). Prevotellaceae UCG001 (7 edges) and UBA1819 (7 edges) were the key genera in the low-density samples (Fig. 4a). Lachnospiraceae NK4A136 (10 edges), Ruminococcaceae UCG014 (9 edges), and Muribaculaceae uncultured bacterium (8 edges) were the key genera in the moderate-density samples (Fig. 4b). The Muribaculaceae uncultured bacterium (13 edges), Raoultella (13 edges), Ruminococcaceae UCG014 (13 edges), Mollicutes RF39 uncultured (13 edges), Erysipelotrichaceae uncultured (13 edges), Ruminiclostridium (13 edges), Ruminiclostridium 5 (13 edges), Marvinbryantia (13 edges), Brevibacillus (13 edges), Prevotellaceae NK3B31 (13 edges), Candidatus Saccharimonas (13 edges), Ruminococcaceae UCG013 (13 edges), Lachnospiraceae UCG006 (13 edges), and Ruminococcaceae uncultured (13 edges) bacterium were the key genera with the most co-occurrent interactions, and Lactobacillus (7 edges) was the key genus

\footnotetext{
(See figure on next page.)

Fig. 2 Differences in the relative abundances of genera affected by nutritional components. a Bar plot indicating the relative abundances of the dominant genera in each sample $(<0.0002 \%)$. $\mathbf{b}$ Heatmap analysis indicating the relative abundances of the dominant genera in various media (<0.02\%). c STAMP analysis indicated the genera that were significantly different between the BL medium and other media. $\mathbf{d}$ Canonical correspondence analysis (CCA) between the gut microbiota community and the related indices (peptone, blood, beef powder, sodium chloride, yeast extract powder, phosphate, glucose, and CFU). The bacteria shown in the panel are dominant genera $(<0.02 \%)$
} 
a Low dilution degrees
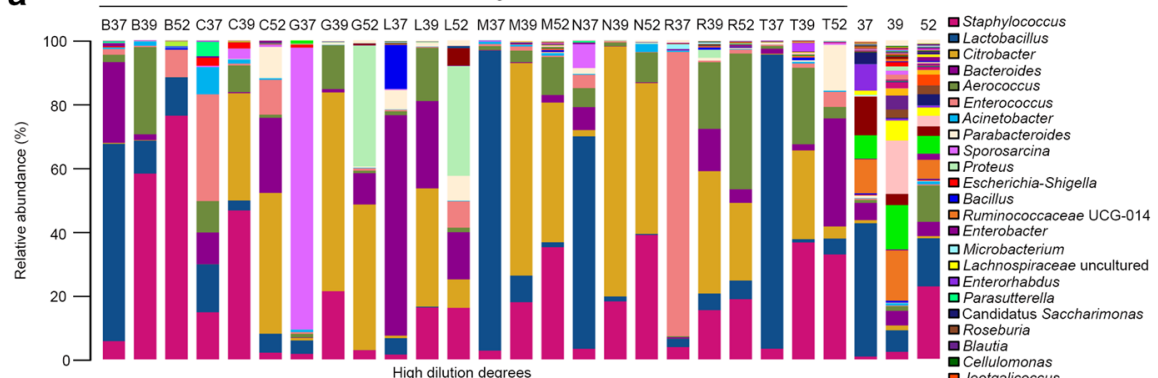

- [Eubacterium] coprostanoligenes group

B37 B39 B52 C37 C39 C52 G37 G39 G52 L37 L39 L52 M37 M39 M52 N37 N39 N52 R37 R39 R52 T37 T39 T52

- Blautia

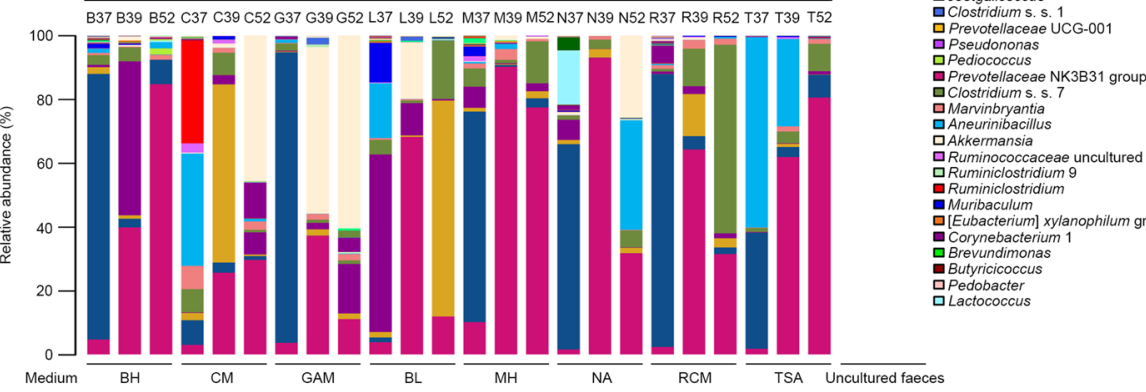

- Facklamia

- Candidatus Arthromitus

Ruminiclostridium 5 UCG-010

[ [Eubacterium] ventriosum group

a Weissella

- Lachnospiraceae UCG-006 Thermoactinomyces
Ruminococcaceae NK4A214 grou
QLachnospiraceae GCA-900066575 - Erysipelatoclostridium

Gastranaerophilales uncultured - Lachnospiraceae
$\square$ Ruminococcus 1 - Cellulosimicrobium Brevibacillus Erysipelotrichaceae uncultured G/utamicibacter - Subdoligranulum Alloprevotella 口Rrevibacterium
Leuconostoc Gphingopyxis - Bradyrhizabium Methylobacterium - Peptostreptococcus 口Ureibacillus
annassigned

b

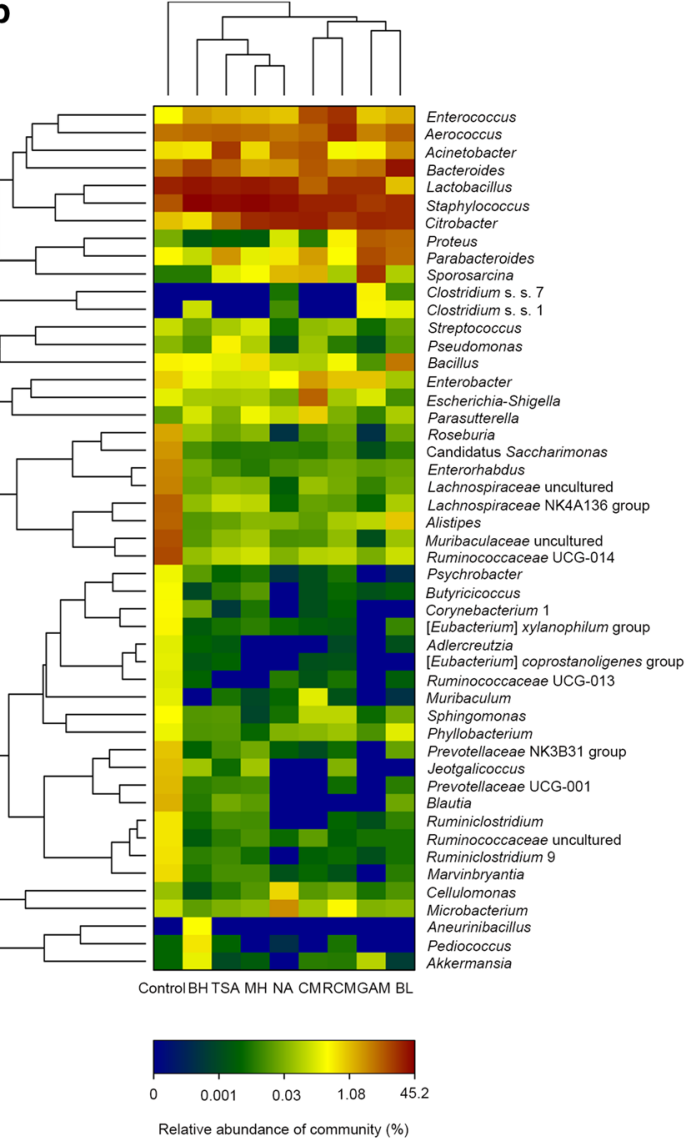

C $\square \mathrm{BL} \square \mathrm{BH} \square \mathrm{CM} \square \mathrm{MH} \square \mathrm{NA} \square \mathrm{RCM} \square \mathrm{TSA}$

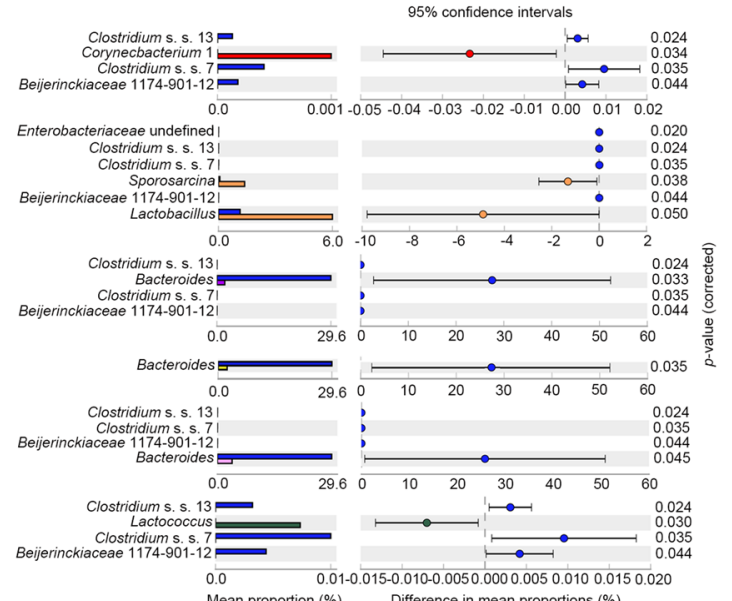

d

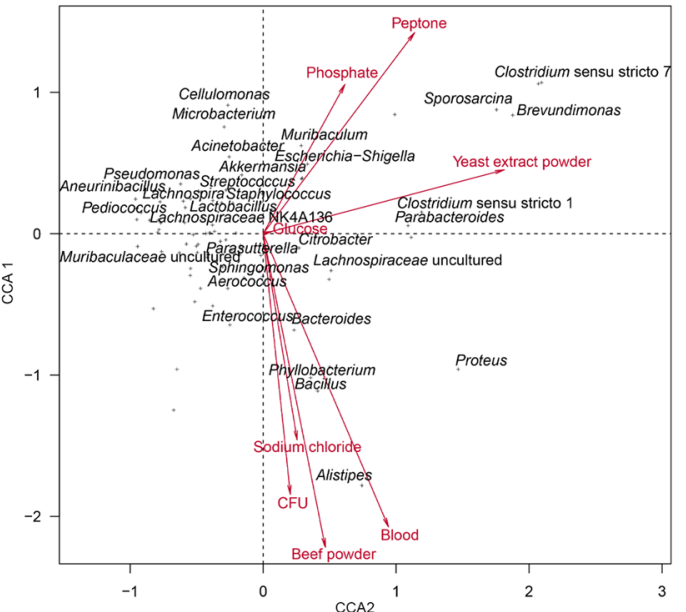


Table 2 Permutation test of Canonical correspondence analysis

\begin{tabular}{llrll}
\hline & CCA1 & \multicolumn{1}{c}{ CCA2 } & $\mathbf{r}^{2}$ & P \\
\hline CFU & 0.2032 & -0.9791 & 0.1596 & $0.038^{*}$ \\
Peptone & 0.6882 & 0.7255 & 0.1523 & $0.022^{*}$ \\
Phosphate & 0.5486 & 0.8361 & 0.0671 & 0.212 \\
Yeast extract powder & 0.9895 & 0.1449 & 0.1842 & $0.011^{*}$ \\
Beef powder & 0.3088 & -0.9511 & 0.2429 & $0.004^{* *}$ \\
Glucose & 0.9910 & 0.1341 & 0.0002 & 0.993 \\
Blood & 0.5165 & -0.8563 & 0.2581 & $0.005^{* *}$ \\
Sodium chloride & 0.2728 & -0.9621 & 0.1030 & 0.076 \\
\hline
\end{tabular}

Significance: ${ }^{* * P}<0.01, * P<0.05$

with mutual exclusion interactions in the high-density samples (Fig. 4c).

\section{Functional prediction under different media and densities of bacterial colonies}

STAMP was applied to further investigate whether the potential functions of gut microbiota on agar plates are typically associated with the nutritional components of medium and the densities of bacterial colonies, and it compared the relative abundance values of the KEGG pathways predicted by the phylogenetic investigation of communities by reconstruction of unobserved states (PICRUSt). To infer the effects of the nutritional components on the functions of microbiota in various media, we examined the L2 metabolic pathways with significant differences among the medium groups (Fig. 5a). Most of the metabolic pathways increased in the BL medium, for example, the cellular processes and signaling pathway was increased compared to that in the BH, RCM, or TSA medium; the biosynthesis and metabolism of glycan was increased compared to that in the NA, TSA, or $\mathrm{MH}$ medium; metabolism of the cofactors and vitamins was increased compared to in the CM, TSA, or RCM medium; energy metabolism was increased compared to that in the CM medium; biosynthesis of other secondary metabolites was increased compared to in the MH medium; and amino acid metabolism was increased comparing to in the RCM medium. Therefore, compared to other the media, the bacterial growth and metabolic processes, such as cellular processes and signaling, glycan
Table 4 Strain information of isolates from TSA medium with 8\% defidrinated sheep's blood

\begin{tabular}{|c|c|c|c|}
\hline Top-hit taxon & Top-hit strain & Similarity (\%) & $\begin{array}{l}\text { Numbers } \\
\text { of strains }\end{array}$ \\
\hline Lactobacillus murinus & NBRC 14221 & 100 & 19 \\
\hline Phocaeicola vulgatus & ATCC 8482 & 99.55 & 1 \\
\hline Parabacteroides distasonis & ATCC 8503 & 98.33 & 1 \\
\hline Parabacteroides distasonis & ATCC 8503 & 98.48 & 2 \\
\hline Parabacteroides distasonis & ATCC 8503 & 98.18 & 3 \\
\hline Bacteroides faecichinchillae & JCM 17102 & 100 & 1 \\
\hline Bacteroides xylanisolvens & $\mathrm{XB1A}$ & 99.7 & 1 \\
\hline $\begin{array}{l}\text { Parasutterella excrementi- } \\
\text { hominis }\end{array}$ & YIT 11859 & 99.7 & 1 \\
\hline
\end{tabular}

biosynthesis and metabolism, and metabolism of cofactors and vitamins, were more active in the BL medium,.

Next, we assessed the effects of density on the functions that had significant differences (Fig. 5b). More functions with significant differences were observed between moderate- and low-density samples. For example, a moderate density promoted membrane transport and cell motility and inhibited amino acid metabolism and xenobiotic biodegradation and metabolism. Compared to the low-density samples, the high-density samples promoted glycan biosynthesis and metabolism. Furthermore, a moderate density promoted membrane transport compared to both the high- and low-density samples. Above all, the nutritional components of the medium and the bacterial colonies densities both changed some predictive functions, which may further influence the viability and growth of bacteria.

\section{Discussion}

The process of isolating more microorganisms with the development of new culture techniques always takes a great amount of effort and time. Moreover, current knowledge is limited on which factors influence the composition and diversity of the cultured gut bacterial communities, and previous studies have focused on blindly obtaining many repeated bacterial colonies using culture methods. To explore a new method of isolating hardto-culture bacteria, we selected eight common media

Table 3 Strain information of isolates from TSA medium

\begin{tabular}{|c|c|c|c|}
\hline Top-hit taxon & Top-hit strain & Similarity (\%) & $\begin{array}{l}\text { Numbers } \\
\text { of strains }\end{array}$ \\
\hline Lactobacillus murinus & NBRC 14221 & 100 & 29 \\
\hline Lactobacillus taiwanensis & DSM 21401 & 99.85 & 9 \\
\hline Staphylococcus hominis subsp. hominis & DSM 20328 & 99.7 & 1 \\
\hline Bifidobacterium animalis subsp. animalis & ATCC 25527 & 100 & 1 \\
\hline
\end{tabular}




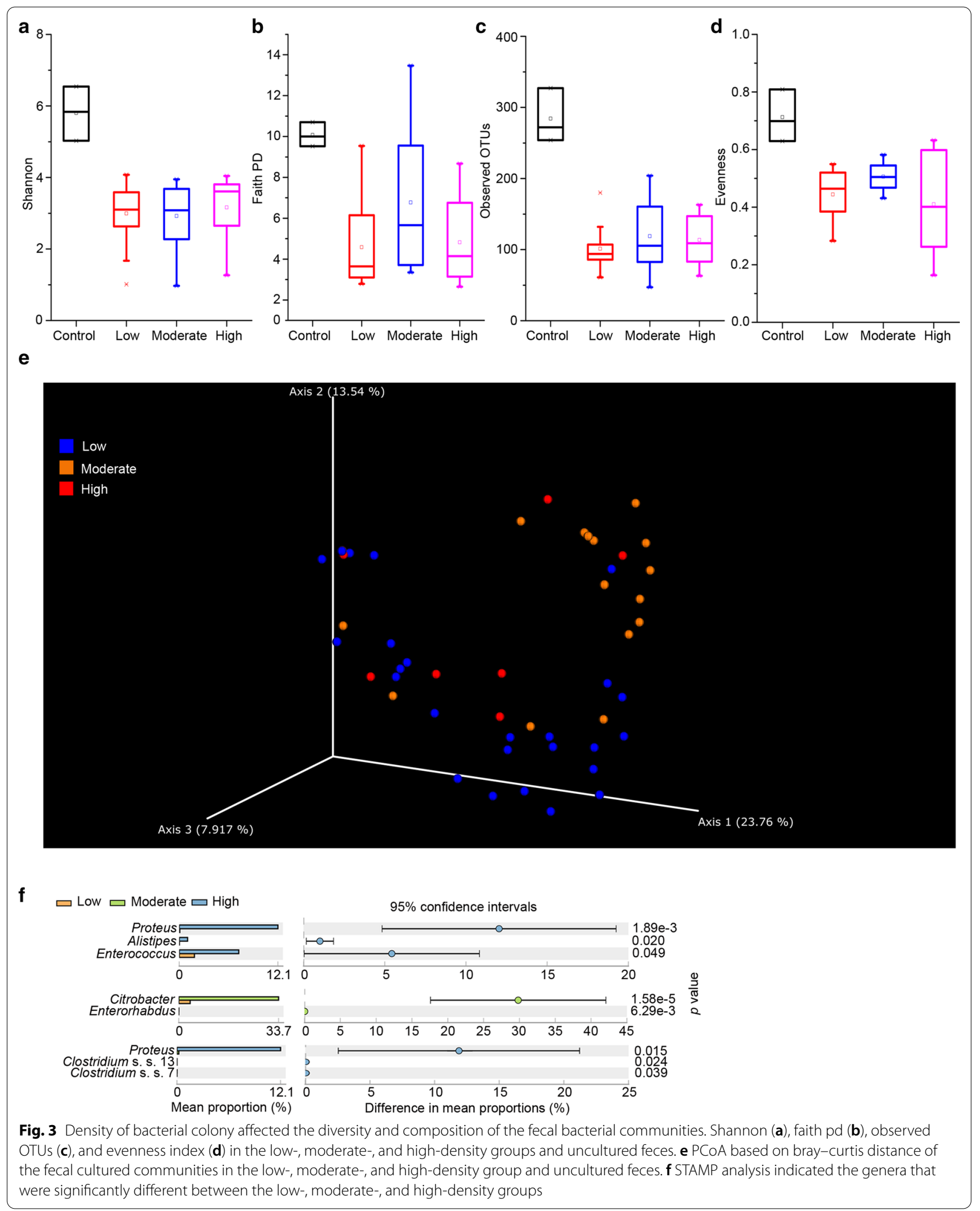




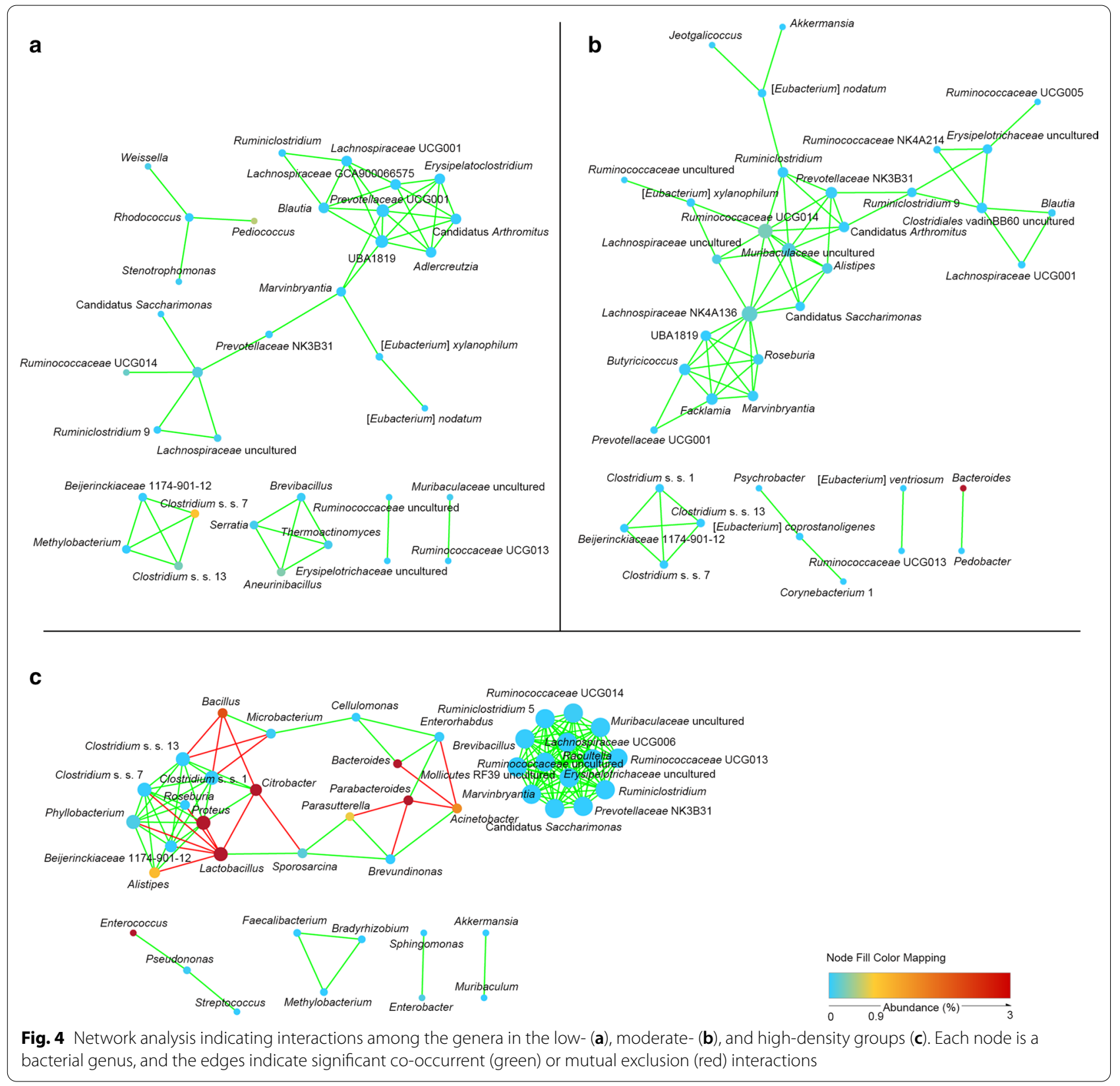

Table 5 Network properties in low-, moderate-, and high-density samples

\begin{tabular}{|c|c|c|c|c|c|}
\hline & Numbers of edges & Numbers of nodes & Average path length & $\begin{array}{l}\text { Clustering } \\
\text { coefficient }\end{array}$ & Heterogeneity \\
\hline Low-density samples & 50 & 34 & 2.84 & 0.47 & 0.60 \\
\hline Moderate-density samples & 67 & 38 & 3.20 & 0.51 & 0.66 \\
\hline High-density samples & 151 & 44 & 1.93 & 0.67 & 0.68 \\
\hline
\end{tabular}


$\mathrm{BL} \square \mathrm{BH} \square \mathrm{CM} \square \mathrm{MH} \square \mathrm{NA} \square \mathrm{RCM} \square \mathrm{TSA}$

Cellular Processes and Signaling Translation

Replication and Repair

Metabolism of Other Amino Acids

Cell Growth and Death

Nucleotide Metabolism

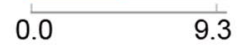

9.3

Energy Metabolism

Metabolism of Cofactors and Vitamins
Signaling Molecules and interaction
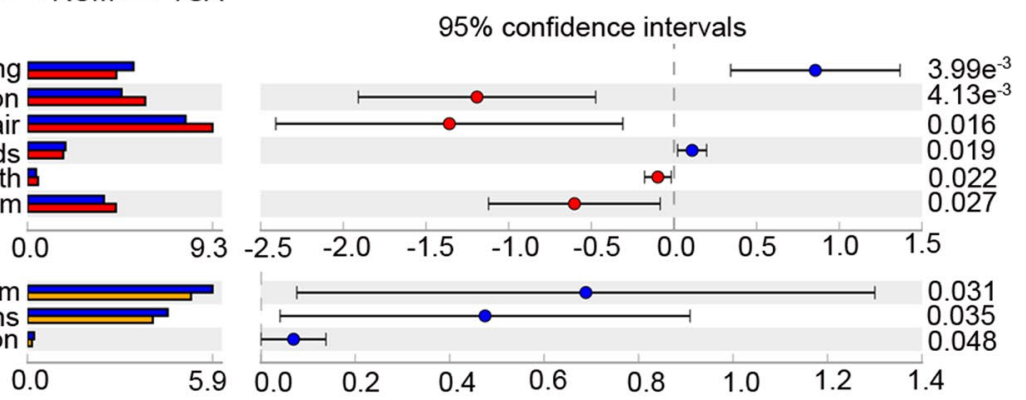

Biosynthesis of Other Secondary Metabolites
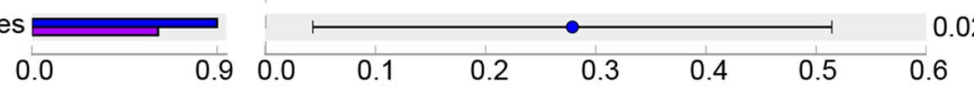

Glycan Biosynthesis and Metabolism

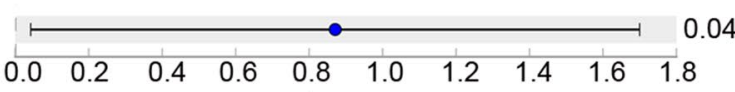

Amino Acid Metabolism
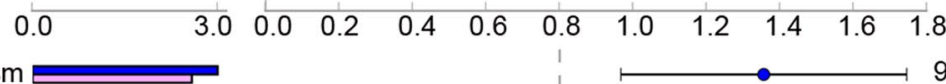

Metabolism of Other Amino Acids

Cellular Processes and Signaling

Metabolism of Cofactors and Vitamins

Biosynthesis of Other Secondary Metabolites $\square$

Transport and Catabolism

Glycan Biosynthesis and Metabolism

Translation

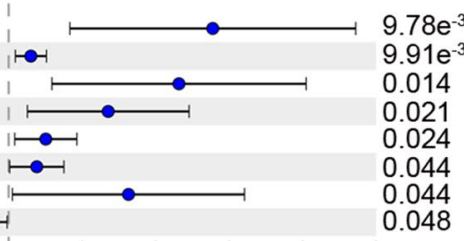

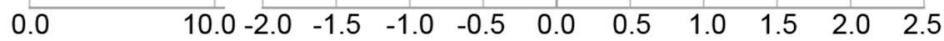

Cellular Processes and Signaling

Glycan Biosynthesis and Metabolism

Metabolism unclassified Enzyme Families

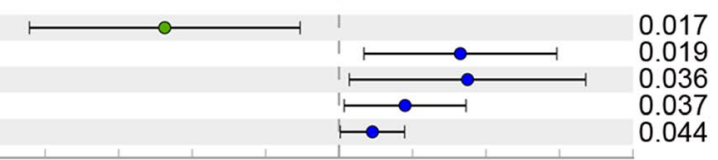

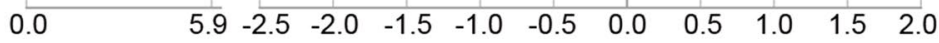

Mean proportion (\%) Difference in mean proportions (\%)

b

$\square$ Low $\square$ Morderate $\square$ High

Metabolism unclassified
Glycan Biosynthesis and Metabolism
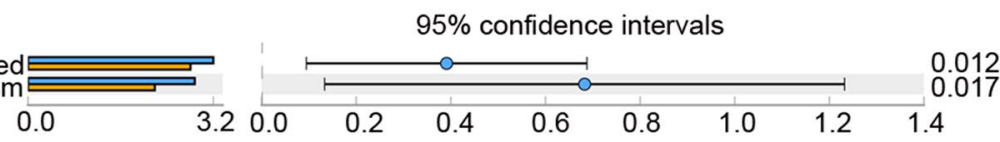

Folding, Sorting, and Degradation日

Metabolism unclassified Transcription

Metabolism of Terpenoids and Polyketides Cell Motility 무 Membrane Transport Energy Metabolism

Amino Acid Metabolism Lipid Metabolism

Xenobiotics Biodegradation and Metabolism

Metabolism of Cofactors and Vitamins

Cell Growth and Death 8

Signal Transduction $\boxminus$

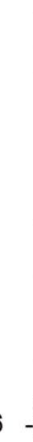

$0.0 \quad 16.6$

Membrane Transport

0.0

$16.6-6$

Mean proportion (\%)

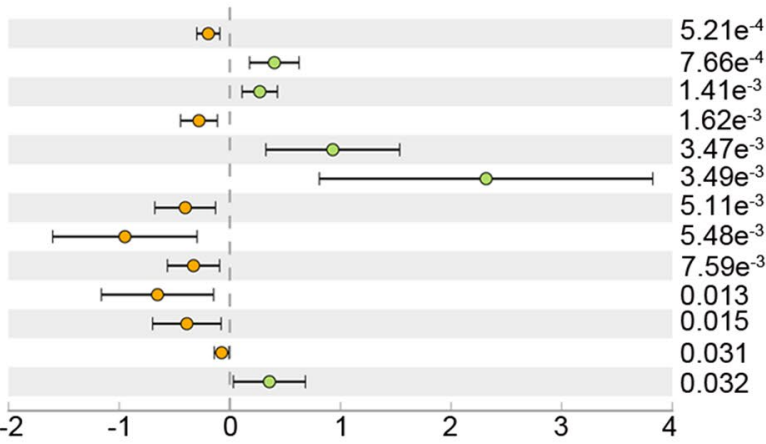

$5.21 \mathrm{e}^{-4}$

$7.66 e^{-4}$

$41 \mathrm{e}^{-3}$

$3.47 e^{-3}$

$3.49 \mathrm{e}^{-3} \cong$

.

$7.59 \mathrm{e}^{-3} \mathrm{a}$

013

0.031

0.032

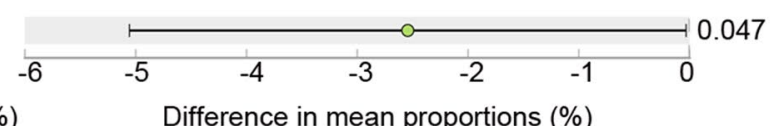

Fig. 5 STAMP analysis indicated the differences of predicted functions in various media (a) and the densities of bacterial colonies (b) 
to enrich gut bacteria on agar plates. Thus, we collected bacterial cultures in various media and analyzed the cultured gut bacterial community using high-throughput sequencing. The results indicated that the different nutritional preferences and densities of the bacterial colonies shaped the various bacterial communities, which suggested that the nutritional components and densities can be adjusted to isolate targeted gut microbiota.

A decrease in gut bacterial diversity was observed after in vitro anaerobic cultivation, which showed there were differences between the in vitro and in vivo environments. Most of the genera enriched in uncultured feces are unculturable bacteria. However, the known genera Alistipes, Enterorhabdus, and Parasutterella were also increased in uncultured feces. According to the description of these three genera, they are obligate anaerobic bacteria, and they can be described as facultative anaerobic bacteria that grow rapidly on agar (Clavel et al. 2009; Nagai et al. 2009; Rautio et al. 2003). This is a possible reason why they are hard to cultivate on agar. In particular, to date, only two and three species have been identified in Enterorhabdus and Parasutterella, respectively.

The medium is the major factor influencing bacterial growth. Culture collections (such as www.atcc.org or www.dsmz.de) recommend species-specific and complex-undefined media for growing individual gut bacteria. Eight common complex-undefined media were used in this study. The bacterial community in BL medium showed a higher diversity compared with the other media. Lagier et al. summarized the 18 optimal culture conditions and identified blood culture bottles, rumen fluid, and sheep blood as the three key nutrient substrates for growing bacteria; the addition of sheep blood increased the isolation rates of the new species, which also indicated the importance of blood in culturing gut bacteria (Lagier et al. 2015, 2016). Furthermore, Bacteroides was enriched significantly in the BL medium, which indicated that it could be isolated in the BL medium. This result is consistent with other studies, and some novel Bacteroides species were isolated using medium containing blood (Bakir et al. 2006a, b; Kitahara et al. 2012; Saputra et al. 2015). Interestingly, 692 unique anaerobic episodes were isolated from the blood cultures in a clinical study, while the Bacteroides spp. accounted for the most colonies (266/692, 38\%) (Rassolie and Özenci 2019). Lactobacillus was significantly decreased in the BL medium compared to all the other media and uncultured feces. Therefore, it is suggested that the BL medium is not suitable for the growth of Lactobacillus. Moreover, Lactobacillus is the most common bacteria isolated from feces as their strong lactic acid production ability allow them to restrain the growth of other bacteria (Merino et al. 2019; Wasfi et al. 2018; Benmouna et al. 2020), which explains the higher diversity in the $\mathrm{BL}$ medium. The results above showed the advantages of the BL medium in cultivating various gut bacteria, while other media can be selected to isolate specific bacteria. For example, we can isolate Aneurinibacillus, Pediococcus, and Akkermansia using BH medium, Microbacterium using NA medium, Muribactulum using $\mathrm{CM}$ medium and so on.

The differences in cultured gut bacterial communities in various media are due to the influence of the nutritional components on the growth of bacteria. According to the clustering results that were based on the nutritional components of the medium, the BL medium was clustered into a single group. The CCA results showed that blood significantly influenced the cultured gut bacterial community. Many blood constituents play important roles in bacterial growth. For example, heme, an essential component of red blood cells, is indispensable for the Porphyromonas gingivalis growth activities (Champagne et al. 2007; Cueno et al. 2014). In contrast, excess heme concentration can be harmful (Lewis 2010; Olczak et al. 2005). For example, many cultured gut bacteria, such as Lactobacillus leichmannii, cannot grow without vitamin B12 supplementation (Kirmiz et al. 2020). Beef powder and peptone both significantly changed the cultured bacterial community, which indicated they have important roles in bacterial growth on agar. Kajihara et al. suggested that the growth rate of Megasphaera elsdenii on KMI medium with a higher ratio of beef extract to peptone was faster than that of other intestinal bacteria (Kajihara et al. 2017). Furthermore, we also observed that these two nutritional components had the opposite effects on bacterial growth. For example, the addition of peptone showed a positive correlation with the relative abundance of Cellulomonas, Microbacterium, etc., while beef powder showed a negative correlation with them. Therefore, determining which nutritional component can enrich which bacteria can provide the basis for adjusting the ratio and concentration of the nutritional components for cultivating the targeted bacteria.

Apart from nutritional components, bacterial interactions are another factor that influences the cultured bacterial community. The number of CFUs significantly influenced the bacterial community (Fig. 2, Table 2). Further analysis revealed that the densities of bacterial colonies have an important effect on the diversity and composition of the bacterial community. A higher diversity of the cultured bacterial community was shown in the moderate-density group, which indicated that too many or too few of the colonies had reduced the bacterial growth on the agar. To survive in complex surrounding communities, bacteria must cooperate and compete with each other (Nadell et al. 2016). Based on our network analysis, when the densities of colonies were low 
or moderate on the agar, the bacteria tended to cooperate with each other. Compared to the low-density group, more cooperating interactions were observed in the moderate-density group, which indicated that the space among the bacterial colonies decreased the cooperating interactions. Cooperation is widely found in bacterial communities, and bacterial communities have cooperative traits, such as diffusible public goods (Harrison et al. 2008). Products that increase individual fitness can also be shared between all members of a population (MacLean 2008). We observed more negative interactions in the high-density group, which suggested that the higher densities caused more competition among the bacterial community. Previous studies reported that bacteria could interact antagonistically by releasing toxins to affect competitors (Bottery et al. 2019; Granato et al. 2019). These toxins were diffusible or delivered toxic effector proteins between the toxin-producing cell and its target cell (Hayes et al. 2010; Sassone-Corsi et al. 2016). Therefore, we can isolate the strain that we wanted by adjusting the inoculation density. For instance, the Citrobacter species can be isolated with a moderate density, the Proteus species with a higher density, etc. In addition, network analysis can also guide the isolation of bacteria. We can try to add the fermentation solution of cooperating bacteria to promote the growth of specific bacteria that are difficult to cultivate. In this way, we can obtain more bacteria that we have not yet cultivated before.

Furthermore, we used functional analysis to understand the biochemical processes of bacteria in different culture conditions. For example, DNA replication and repair, translation, nucleotide metabolism, cell growth and death were enhanced in the $\mathrm{BH}$ medium, which implied that nutritional components attributed to the growth of bacteria and metabolism tended to be vigorous compared to the BL medium. Metabolism, including energy, cofactors and vitamins, glycans, secondary metabolites, etc., was enhanced in the BL medium, indicating that the $\mathrm{BL}$ medium provided rich nutrition for bacterial growth and metabolism. In addition, the density of the bacterial colonies also causes differences in the bacterial functions. Surprisingly, the greatest differences were observed between the moderate- and low-density groups and not between the high- and low-density groups. It is suspected that competing interactions kill more bacteria and make the functional activity of bacteria in the highdensity group similar to that in the low-density group. Membrane transport was significantly enriched in the moderate-density group compared to both the low- and high-density groups. Transport proteins that have sensory purposes in the downstream activation of two-component systems have been described in several bacterial species. For example, the presence of bacitracin is sensed via the activity of the $A B C$ transporter $B c e A B$ of $B$. subtilis. The external and cytoplasmic levels of the antibiotic bacitracin influence the activity of the $A B C$ transporter protein $\mathrm{Bce} A \mathrm{~B}$ and increase the transcription of transporter genes and other related functions (Alvarado et al. 2020; Fritz et al. 2015; Radeck et al. 2017). These studies confirmed the potential pathway by which density influences the function of membrane transport.

In conclusion, our data suggest that both the nutritional components and densities of bacterial colonies influences the gut bacterial community on agar plates. Medium supplementation with blood can increase the diversity of the bacterial community. In addition, beef powder and peptone are important factors that can significantly change the culture-enriched bacterial community. We observed that a moderate density (100-150 CFUs per plate) was optimal for ensuring a higher diversity on the agar. Similarly, the function of membrane transport was significantly enriched in the moderate-density group, which indicated a more active metabolism on the agar plates with this density range. Our work elucidated the optimal culture conditions, including the densities of colonies and nutritional components for various gut bacteria, which provides a novel strategy for the targeted isolation of bacteria that avoids blindness and repetitive work. Furthermore, many competing and cooperative interactions were observed among the culture-enriched bacterial communities, which will encourage more researchers to isolate uncultured bacteria by supplementation with culture that is filtrated with one single or mixed specific bacteria in the medium. In the future, the mechanism by which nutrient components regulate bacterial growth and interactions will require further study.

\section{Abbreviations}

PCOA: Principle coordination analysis; STAMP: Statistical analysis of metagenomics profiles software; CFU: Colony-forming unit; CCA: Canonical correspondence analysis; PICRUSt: Phylogenetic investigation of communities by reconstruction of unobserved states; GAM: Modified Gifu anaerobic medium; $\mathrm{BH}$ : Brain-heart infusion medium; CM: Chopped meat medium; NA: Nutrient agar medium; TSA: Tryptic soy agar medium; RCM: Reinforced clostridial medium; MH: Mueller-Hinton medium; BL: Blood medium; OTUs: Operational taxonomic units.

\section{Supplementary Information}

The online version contains supplementary material available at https://doi. org/10.1186/s13568-021-01240-6.

Additional file 1: Figure S1. Rarefaction curves in all samples. Figure S2. Correlation and cluster analysis of nutritional components in medium based on Spearman correlation coefficient.

Additional file 2: Table S1: Relative abundance of fecal bacteria in genus level. Table S2: The numbers of CFU in various media (CFU/plate). 


\section{Acknowledgements \\ Not applicable.}

\section{Authors' contributions}

D. Y. designed the study. Y. G., P. L., J. W., and Y. C. performed fecal sample collection and culture plating, M. L., S. D., and S. N. extracted the fecal DNA. D. Y. and M. W. analyzed the data from culture and sequencing. M. Y. and J. L. conducted the strain isolation. D. Y. and Y. G. wrote the paper drafts. M. W., M. L., and F. Y. reviewed and edited the manuscript drafts. All authors have read and approved the final manuscript.

\section{Funding}

This research was supported by the Key Scientific Research Projects for Higher Education of Henan Province (No. 20A310012), the Science and Technology Research Project of Henan Province (No. 192102310169, 202102310270), the National Natural Science Foundation of China (No. 32000006), and the Doctoral Scientific Research Activation Foundation of the Xinxiang Medical University (No. 505287). The funding bodies had no role in the design of the study and collection, analysis, and interpretation of data and in writing the manuscript.

\section{Availability of data and materials}

The data generated or analyzed during this study are included in this published article and its Additional file. The raw reads were deposited into the NCBI Sequence Read Archive (SRA) database under accession number SRP249932.

\section{Declarations}

\section{Ethics approval and consent to participate}

The animal experiments were conducted in accordance with the principles provided by the National Institutes of Health's Guide for the Care and Use of Laboratory Animals., and the experimental protocol was approved by the Institutional Animal Care and Use Committee of the Xinxiang Medical University,

\section{Consent for publication}

Not applicable.

\section{Competing interests}

The authors declare no conflicts of interest.

\section{Author details}

${ }^{1}$ Xinxiang Key Laboratory of Pathogenic Biology, Department of Microbiology, School of Basic Medical Sciences, Xinxiang Medical University, 601 Jinsui Road, Hongqi District, Xinxiang 453003, Henan, China. ${ }^{2}$ Laboratory of Genetic Regulators in the Immune System, Henan Collaborative Innovation Center of Molecular Diagnosis and Laboratory Medicine, School of Laboratory Medicine, Xinxiang Medical University, Xinxiang 453003, Henan, China.

Received: 3 January 2021 Accepted: 24 May 2021

Published online: 31 May 2021

\section{References}

Abt MC, Osborne LC, Monticelli LA, Doering TA, Alenghat T, Sonnenberg GF, Paley MA, Antenus M, Williams KL, Erikson J, Wherry EJ, Artis D (2012) Commensal bacteria calibrate the activation threshold of Innate antiviral immunity. Immunity 37:158-170

Alain K, Querellou J (2009) Cultivating the uncultured: limits, advances and future challenges. Extremophiles 13:583-594

Alvarado A, Behrens W, Josenhans C (2020) Protein activity sensing in bacteria in regulating metabolism and motility. Front Microbiol 10:3055. https:// doi.org/10.3389/fmicb.2019.03055

Bäckhed F, Ley RE, Sonnenburg JL, Peterson DA, Gordon J (2005) Host-bacterial mutualism in the human intestine. Science 307:1915-1920. https:// doi.org/10.1126/science.1104816
Bakir MA, Kitahara M, Sakamoto M, Matsumoto M, Benno Y (2006a) Bacteroides finegoldii sp. nov., isolated from human faeces. Int J Syst Evol Microbiol 56:931-935. https://doi.org/10.1099/ijs.0.64084-0

Bakir MA, Sakamoto M, Kitahara M, Matsumoto M, Benno Y (2006b) Bacteroides dorei sp. nov., isolated from human faeces. Int I Syst Evol Microbiol 56:1639-1643. https://doi.org/10.1099/ijs.0.64257-0

Benmouna Z, Dalache F, Zadi-Karam H, Karam NE, Vuotto C (2020) Ability of three lactic acid bacteria to grow in sessile mode and to inhibit biofilm formation of pathogenic bacteria. Advances in experimental medicine and biology. Springer, New York

Bolyen E, Rideout JR, Dillon MR, Bokulich NA, Abnet CC, Al-Ghalith GA, Alexander HA, Eric J, Arumugam M, Asnicar F, Bai Y, Bisanz JE, Bittinger K, Brejnrod A, Brislawn CJ, Brown CT, Callahan BJ, Caraballo Rodríguez AM, Chase J, Cope EK, Da Silva R, Diener C, Dorrestein PC, Douglas GM, Durall DM, Duvallet C, Edwardson CF, Ernst M, Estaki M, Fouquier J, Gauglitz JM, Gibbons SM, Gibson DL, Gonzalez A, Gorlick K, Guo J, Hillmann B, Holmes S, Holste H, Huttenhower C, Huttley GA, Janssen S, Jarmusch AK, Jiang L, Kaehler BD, Kang KB, Keefe CR, Keim P, Kelley ST, Dan K, Koester I, Kosciolek T, Kreps J, Langille MGl, Lee J, Ley R, Liu YX, Loftfield E, Lozupone C, Maher M, Marotz C, Martin BD, McDonald D, Mclver LJ, Melnik AV Metcalf JL, Morgan SC, Morton JT, Naimey AT, Navas-Molina JA, Nothias LF, Orchanian SB, Pearson T, Peoples SL, Petras D, Preuss ML, Pruesse E, Rasmussen LB, Rivers A, Robeson MS, Rosenthal P, Segata N, Shaffer M, Shiffer A, Sinha R, Song SJ, Spear JR, Swafford AD, Thompson LR, Torres PJ, Trinh P, Tripathi A, Turnbaugh PJ, UI-Hasan S, van der Hooft JJJ, Vargas F, Vázquez-Baeza Y, Vogtmann E, von Hippel M, Walters W, Wan Y, Wang M, Warren J, Weber KC, Williamson CHD, Willis AD, Xu ZZ, Zaneveld JR, Zhang Y, Zhu Q, Knight R, Caporaso JG (2019) Reproducible, interactive, scalable and extensible microbiome data science using QIIME 2. Nat Biotechnol 37:852-857. https://doi.org/10.1038/s41587-019-0209-9

Bottery MJ, Passaris I, Dytham C, Wood AJ, van der Woude MW (2019) Spatial organization of expanding bacterial colonies Is affected by contactdependent growth inhibition. Curr Biol 29:3622-3634 e3625. https://doi. org/10.1016/j.cub.2019.08.074

Champagne CM, Holt SC, Van Dyke TE, Gordon BJ, Shapira L (2007) Lipopolysaccharide isolated from Porphyromonas gingivalis grown in hemin-limited chemostat conditions has a reduced capacity for human neutrophil priming. Oral Microbiol Immun 11:319-325

Clavel T, Charrier C, Braune A, Wenning M, Blaut M, Haller D (2009) Isolation of bacteria from the ileal mucosa of TNFdeltaARE mice and description of Enterorhabdus mucosicola gen. nov., sp. nov. Int J Syst Evol Microbiol 59:1805-1812. https://doi.org/10.1099/ijs.0.003087-0

Clemente JC, Ursell LK, Parfrey LW, Knight R (2012) The impact of the gut microbiota on human health: an integrative view. Cell 148:1258-1270

Cueno ME, Tamura M, Ohya M, Ochiai K (2014) Similar physiological effects in Porphyromonas gingivalis ATCC 33277 under hemin-excess and heminlimited concentrations are putatively associated to different hydrogen peroxide function. Anaerobe 28:178-181

Edgar RC (2016) UNOISE2: improved error-correction for Illumina 165 and ITS amplicon sequencing. bioRxiv. https://doi.org/10.1101/081257

Faust K, Sathirapongsasuti JF, Izard J, Segata N, Gevers D, Raes J, Huttenhower C (2012) Microbial co-occurrence relationships in the human microbiome. PLoS Comput Biol 8:e1002606. https://doi.org/10.1371/journal.pcbi. 1002606

Fritz G, Dintner S, Treichel NS, Radeck J, Gerland U, Mascher T, Gebhard S (2015) A new way of sensing: need-based activation of antibiotic resistance by a flux-sensing mechanism. Mbio 6:e00975-00915

Granato ET, Meiller-Legrand TA, Foster KR (2019) The evolution and ecology of bacterial warfare. Curr Biol 29:R521-R537. https://doi.org/10.1016/j.cub. 2019.04.024

Harrison F, Paul J, Massey RC, Buckling A (2008) Interspecific competition and siderophore-mediated cooperation in Pseudomonas aeruginosa. ISME J 2:49-55. https://doi.org/10.1038/ismej.2007.96

Hayes CS, Aoki SK, Low DA (2010) Bacterial contact-dependent delivery systems. Annu Rev Genet 44:71-90

Huws SA, Edwards JE, Kim EJ, Scollan ND (2007) Specificity and sensitivity of eubacterial primers utilized for molecular profiling of bacteria within complex microbial ecosystems. J Microbiol Methods 70:565-569

lida N, Dzutsev A, Stewart CA, Smith L, Bouladoux N, Weingarten RA, Molin DA, Salcedo R, Back T, Cramer S, Dai RM, Kiu H, Cardone M, Naik S, Patri AK, Wang E, Marincola FM, Frank KM, Belkaid Y, Trinchieri G, Goldszmid 
RS (2013) Commensal bacteria control cancer response to therapy by modulating the tumor microenvironment. Science 342:967-970

Jung D, Seo EY, Epstein SS, Joung Y, Han J, Parfenova WV, Belykh OI, Gladkikh AS, Ahn TS (2015) Application of a new cultivation technology, I-tip, for studying microbial diversity in freshwater sponges of Lake Baikal, Russia. FEMS Microbiol Ecol 90:417-423

Kajihara Y, Yoshikawa S, Cho Y, Ito T, Miyamoto H, Kodama H (2017) Preferential isolation of Megasphaera elsdenii from pig feces. Anaerobe 48:160-164

Kirmiz N, Galindo K, Cross KL, Luna E, Rhoades N, Podar M, Flores GE (2020) Comparative genomics guides elucidation of vitamin $B_{12}$ biosynthesis in novel human-associated Akkermansia Strains. Appl Environ Microb 86:e2117-02119. https://doi.org/10.1128/AEM.02117-19

Kitahara M, Sakamoto M, Tsuchida S, Kawasumi K, Amao H, Benno Y, Ohkuma M (2012) Bacteroides stercorirosoris sp. nov. and Bacteroides faecichinchillae sp. nov., isolated from chinchilla (Chinchilla lanigera) faeces. Int I Syst Evol Microbiol 62:1145-1150. https://doi.org/10.1099/ijs.0.032706-0

Lagier JC, Armougom F, Million M, Hugon P, Pagnier I, Robert C, Bittar F, Fournous G, Gimenez G, Maraninchi M, Trape JF, Koonin EV, La Scola B, Raoult D (2012) Microbial culturomics: paradigm shift in the human gut microbiome study. Clin Microbiol Infect 18:1185-1193

Lagier JC, Hugon P, Khelaifia S, Fournier P-E, La Scola B, Raoult D (2015) The rebirth of culture in microbiology through the example of culturomics to study human gut microbiota. Clin Microbiol Rev 28:237-264

Lagier JC, Khelaifia S, Alou MT, Ndongo S, Dione N, Hugon P, Caputo A, Cadoret F, Traore SI, Seck EH, Dubourg G, Durand G, Mourembou G, Guilhot E, Togo A, Bellali S, Bachar D, Cassir N, Bittar F, Delerce J, Mailhe M, Ricaboni D, Bilen M, Dangui Nieko NP, Dia Badiane NM, Valles C, Mouelhi D, Diop K, Million M, Musso D, Abrahao J, Azhar El, Bibi F, Yasir M, Diallo A, Sokhna C, Djossou F, Vitton V, Robert C, Rolain JM, La Scola B, Fournier PE, Levasseur A, Raoult D (2016) Culture of previously uncultured members of the human gut microbiota by culturomics. Nat Microbiol 1:16203. https://doi. org/10.1038/nmicrobiol.2016.203

Lagier JC, Dubourg G, Million M, Cadoret F, Bilen M, Fenollar F, Levasseur A, Rolain JM, Fournier PE, Raoult D (2018) Culturing the human microbiota and culturomics. Nat Rev Microbiol 16:540-550. https://doi.org/10.1038/ s41579-018-0041-0

Langille MGI, Zaneveld J, Caporaso JG, McDonald D, Knights D, Reyes JA, Clemente JC, Burkepile DE, Vega Thurber RL, Knight R, Beiko RG, Huttenhower C (2013) Predictive functional profiling of microbial communities using 16S rRNA marker gene sequences. Nat Biotechnol 31:814-821

Leadbetter JR, Schmidt TM, Graber JR, Breznak JA (1999) Acetogenesis from $\mathrm{H}_{2}$ plus $\mathrm{CO}_{2}$ by spirochetes from termite guts. Science 283:686-689

Lewis JP (2010) Metal uptake in host-pathogen interactions: role of iron in Porphyromonas gingivalis interactions with host organisms. Periodontol 2000 52:94-116

Li WJ, Xu P, Schumann P, Zhang YQ, Pukall R, Xu LH, Stackebrandt E, Jiang CL (2007) Georgenia ruanii sp. nov., a novel actinobacterium isolated from forest soil in Yunnan (China), and emended description of the genus Georgenia. Int J Syst Evol Microbiol 57:1424

MacLean RC (2008) The tragedy of the commons in microbial populations: insights from theoretical, comparative and experimental studies. Heredity 100:233-239. https://doi.org/10.1038/sj.hdy.6801073

Merino L, Trejo FM, De Antoni G, Golowczyc MA (2019) Lactobacillus strains inhibit biofilm formation of Salmonella sp. isolates from poultry. Food Res Int 123:258-265

Nadell CD, Drescher K, Foster KR (2016) Spatial structure, cooperation and competition in biofilms. Nat Rev Microbiol 14:589-600

Nagai F, Morotomi M, Sakon H, Tanaka R (2009) Parasutterella excrementihominis gen. nov., sp. nov., a member of the family Alcaligenaceae isolated from human faeces. Int J Syst Evol Microbiol 59:1793-1797. https://doi. org/10.1099/ijs.0.002519-0

OlczakT, Simpson W, Liu X, Genco CA (2005) Iron and heme utilization in Porphyromonas gingivalis. FEMS Microbiol Rev 29:119-144

Parks DH, Tyson GW, Hugenholtz P, Beiko RG (2014) STAMP: statistical analysis of taxonomic and functional profiles. Bioinformatics 30:3123

Patterson E, Ryan PM, Cryan JF, Dinan TG, Ross RP, Fitzgerald GF, Stanton C (2016) Gut microbiota, obesity and diabetes. Postgrad Med J 92:286-300. https://doi.org/10.1136/postgradmedj-2015-133285
Qin J, Li R, Raes J, Arumugam M, Burgdorf KS, Manichanh C, Nielsen T, Pons N, Levenez F, Yamada T, Mende DR, Li J, Xu J, Li S, Li D, Cao J, Wang B, Liang H, Zheng H, Xie Y, Tap J, Lepage P, Bertalan M, Batto JM, Hansen T, Le Paslier D, Linneberg A, Nielsen HB, Pelletier E, Renault P, Sicheritz-Ponten T, Turner K, Zhu H, Yu C, Li S, Jian M, Zhou Y, Li Y, Zhang X, Li S, Qin N, Yang H, Wang J, Brunak S, Doré J, Guarner F, Kristiansen K, Pedersen O, Parkhill J, Weissenbach J, Antolin M, Artiguenave F, Blottiere H, Borruel N, Bruls T, Casellas F, Chervaux C, Cultrone A, Delorme C, Denariaz G, Dervyn R, Forte M, Friss C, van de Guchte M, Guedon E, Haimet F, Jamet A, Juste C, Kaci G, Kleerebezem M, Knol J, Kristensen M, Layec S, Le Roux K, Leclerc M, Maguin E, Melo Minardi R, Oozeer R, Rescigno M, Sanchez N, Tims S, Torrejon T, Varela E, de Vos W, Winogradsky Y, Zoetendal E, Bork P, Ehrlich SD, Wang J, Meta HITC (2010) A human gut microbial gene catalogue established by metagenomic sequencing. Nature 464:59-65. https://doi. org/10.1038/nature08821

Qin J, Li Y, Cai Z, Li S, Zhu J, Zhang F, Liang S, Zhang W, Guan Y, Shen D (2012) A metagenome-wide association study of gut microbiota in type 2 diabetes. Nature 490:55-60. https://doi.org/10.1038/nature1 1450

Radeck J, Fritz G, Mascher T (2017) The cell envelope stress response of Bacillus subtilis: from static signaling devices to dynamic regulatory network. Curr Genet 63:1-12

Rassolie A, Özenci V (2019) Short-term culture for rapid identification of anaerobic bacteria from blood cultures. Anaerobe 57:59-62. https://doi. org/10.1016/j.anaerobe.2019.03.014

Rautio M, Eerola E, Vaisanen-Tunkelrott ML, Molitoris D, Lawson P, Collins MD, Jousimies-Somer H (2003) Reclassification of Bacteroides putredinis (Weinberg et al., 1937) in a new genus Alistipes gen. nov., as Alistipes putredinis comb. nov., and description of Alistipes finegoldii sp. nov., from human sources. Syst Appl Microbiol 26:182-188. https://doi.org/10.1078/07232 0203322346029

Saito R, Smoot ME, Ono K, Ruscheinski J, Wang PL, Lotia S, Pico AR, Bader GD, Ideker T (2012) A travel guide to Cytoscape plugins. Nat Methods 9:1069-1076. https://doi.org/10.1038/nmeth.2212

Saputra S, Irisawa T, Sakamoto M, Kitahara M, Sulistiani YT, Ohkuma M, Dinoto A (2015) Bacteroides caecigallinarum sp. nov., isolated from caecum of an Indonesian chicken. Int J Syst Evol Microbiol 65:4341-4346. https://doi. org/10.1099/ijsem.0.000573

Sassone-Corsi M, Nuccio SP, Liu H, Hernandez D, Vu CT, Takahashi AA, Edwards RA, Raffatellu M (2016) Microcins mediate competition among Enterobacteriaceae in the inflamed gut. Nature 540:280-283. https://doi.org/10. 1038/nature20557

Stevenson BS, Eichorst SA, Wertz JT, Schmidt TM, Breznak JA (2004) New strategies for cultivation and detection of previously uncultured microbes. Appl Environ Microbiol 70:4748-4755

Takeshi I, Pang IK, Kumamoto Y, Peaper DR, Ho JH, Murray TS, Iwasaki A, Littman DR (2011) Microbiota regulates immune defense against respiratory tract influenza A virus infection. Proc Natl Acad Sci U S A 108:5354-5359

Team RC (2018) R: a language and environment for statistical computing. $R$ Foundation for Statistical Computing, Vienna, Austria. http://www.r-proje ct.org.

Wasfi R, El-Rahman OAA, Mai MZ, Ashour HM (2018) Probiotic Lactobacillus sp. inhibit growth, biofilm formation and gene expression of caries-inducing Streptococcus mutans. J Cell Mol Med 22:1972-1983

Wong SH, Yu J (2019) Gut microbiota in colorectal cancer: mechanisms of action and clinical applications. Nat Rev Gastroenterol Hepatol 16:1-15. https://doi.org/10.1038/s41575-019-0209-8

Yoon SH, Ha SM, Kwon S, Lim J, Chun J (2017) Introducing EzBioCloud: a taxonomically united database of $16 \mathrm{~S}$ rRNA gene sequences and wholegenome assemblies. Int J Syst Evol Microbiol 67:1613-1617

\section{Publisher's Note}

Springer Nature remains neutral with regard to jurisdictional claims in published maps and institutional affiliations. 